\title{
PROPUESTA PARA ANALIZAR EL GATO NEGRO DE EDGAR ALLAN POE, LA NOVELA MARIANELA DE BENITO PÉREZ GALDÓS Y LAS RIMAS DE GUSTAVO ADOLFO BÉCQUER
}

\author{
Catalina Ramírez Molina \\ Profesora de la Escuela de Formación Docente \\ de la Universidad de Costa Rica \\ San José, Costa Rica
}

Recibido 7-XI-2007 • Aceptado 13-XI-2007 • Corregido 2-III-2008

"Si nuestro primer encuentro con el libro fue de feliz alegría, adónde fuimos felices alguna vez, allí todos volvemos"

Enrique Obregón

\begin{abstract}
Resumen: La intención de la siguiente propuesta de análisis para los textos literarios: El gato negro, Marianela y las Rimas es cumplir con los objetivos planteados por el MEP, articular los contenidos con las actividades o estrategias de aprendizaje y desarrollar un aprendizaje significativo.

Con respecto al género lírico, se proponen algunos cambios en los contenidos, ya que, a través del artículo titulado Estrategias metodológicas utilizadas por docentes de sétimo año en la enseñanza del análisis de textos literarios, se muestra que los alumnos poseen actitudes hostiles hacia este género del discurso, debido a la forma en que se han acercado a él. Por esta razón, para que los estudiantes sean capaces de dialogar con el género lírico, de profundizar en su mensaje, de interpretarlo y disfrutarlo, es preciso que lleguen a desarrollar una sensibilidad y que adquieran ciertas competencias lingüisticas, culturales y esteticoliterarias.

Es importante señalar que el planeamiento de las actividades para analizar cada texto literario cambia, es decir, un cuento romántico no puede ser analizado de la misma manera que un cuento naturalista. De esta manera, la siguiente propuesta es sólo una guía,
\end{abstract}

\section{Introducción}

Esta propuesta de análisis nace con el propósito de articular los objetivos y contenidos que plantea el Ministerio de Educación Pública para analizar textos literarios con sétimos años. La propuesta parte de los objetivos y contenidos del Plan de Estudios de Español, sin embargo, en el género lírico se proponen algunos cambios en los contenidos.

La prioridad de esta propuesta es unificar criterios metodológicos y literarios para enseñar literatura de una manera significativa, dinámica, creativa e interactiva y a la vez recordar que cada docente debe trabajar en el ordenamiento metodológico de los conocimientos que imparte, tomando en cuenta los recursos de la institución y principalmente, el contexto sociocultural de sus estudiantes. 
debido a que cada texto posee características particulares que deben ser analizadas por el docente antes de planificar la clase.

Palabras clave: Propuesta, análisis literario, cuento, novela, poesía.

Abstract: The purpose of the following proposal for the analysis of the literary texts aforementioned is to comply with the objectives established by the MEP that promotes the matching of contents with the activities or teaching strategies and the development of significant learning experiences.

Concerning the lyrical genre, some content changes are proposed because in the article Methodological Strategies Used by 7 th Grade Instructors to Teach the Analysis of Literary Texts, it was clearly seen that most students show certain disdain towards this discourse due to the way in which it has been approached. For this reason, for students to be able to interact with the lyrical text, get deeper into its message, interpret it, and enjoy it, it is necessary for them to develop their sensibility and to acquire certain linguistic, cultural, and aesthetic-literary competence.

It is imperative to point out that the planning of activities for the analysis of literary texts is not static, for example, the teaching plan for a romantic short story varies significantly from the planning required for a naturalist story. In this way, the following proposal is simply a guideline as long as each text has particular characteristics that have to be analyzed by the teacher before planning his/her class.

Key words: Proposal, literary analysis, short story, novel, poetry.

\section{Objetivos}

- Reconocer la lengua literaria como sistema ficcional, connotativo, plurisignificativo, dialógico-cultural.

- Promover un acercamiento plural, creativo y crítico al texto escrito.

- Fomentar el disfrute de la lectura.

\section{Contenidos}

Los contenidos de los géneros literarios cuento y novela son:

Análisis de los siguientes elementos:

- Narrador: Tipos (omnisciente, testigo y protagonista); visiones (narrador $>$ personajes, narrador $<$ personajes narrador=personajes); organización secuencial de la historia narrada (lineal o perturbada); código apreciativo (valoración de las partes del mundo mostrado); tiempo; mundo mostrado: espacios (físico, jurídico, ético, religioso, educativo, económico, político, social, ecológico o psicológico, cuando los haya); personajes (lo que dicen ser y lo que hacen) su interacción con los otros, su código apreciativo (valoración del mundo mostrado).

Relaciones del texto con el contexto sociocultural, con el género y los movimientos literarios.

\section{Lírica}

- Hablante o yo lírico: código apreciativo.

- Organización del universo lírico: especial unidad de motivación entre forma y contenido: verso (métrica, rima, ritmo, formas estróficas); figuras literarias (prosopopeya, símil, metáfora e hipérbole) y figuras de construcción (anáfora, reiteración, encabalgamiento). 
- Relaciones del texto con el contexto sociocultural, con el género literario y con los movimientos romántico y modernista.

\section{Valores y actitudes}

- $\quad$ Aprecio por la lectura y el análisis literario como un encuentro de la actividad intelectual y de la aventura de la imaginación.

- Reconocimiento de la literatura como componente fundamental de la cultura.

\section{Criterios de evaluación}

- Analiza, en textos específicos, las características predominantes de la épica y la lírica.

- Reconoce, en textos específicos, las características de los movimientos literarios.

- Ministerio de Educación Pública. (2005). Programa de estudios. Español I y II ciclo de Educación General Básica, pp. 31-32. San José, Costa Rica: Departamento de Publicaciones, Ministerio de Educación Pública.

\section{Cuento El gato negro de Edgar Allan Poe}

Como se mostró en el artículo titulado Estrategias metodológicas utilizadas por docentes de sétimo año en la enseñanza del análisis de textos literarios, en una de las observaciones que se realizaron, en la clase de una de las docentes, en la que leían $\boldsymbol{E l}$ Gato negro, se encontró que los estudiantes mostraban interés por una serie televisiva llamada CSI, Las Vegas. Esta serie plasma las realidades en las calles estadounidenses, en donde un grupo de forenses, detectives, microbiólogos y criminalistas, investigan y recrean escenas de asesinatos, suicidios, entre otros. A través de la búsqueda de pistas y confesiones de testigos, logran resolver el caso.

Sin duda, para los estudiantes esta serie guarda una relación directa con el cuento. Por ello, la primera actividad que se propone para analizar el texto, es partir de sus intereses. Por esta razón, la docente dejará como tarea ver la serie.

Posteriormente, se comentará en clase cuál es la dinámica del programa, con el fin de que los alumnos expresen su temática. En este punto, la docente explicará que, como lectores, serán los que identifiquen y reconstruyan los sucesos del cuento. En esta etapa, la docente motivará a sus alumnos y trasmitirá la idea de que ellos serán como ese equipo profesional de CSI que reconstruirá la escena del crimen. Esta actividad funciona como motivación para que el alumno se interese en el texto, logre comprenderlo y disfrutarlo.

Con el propósito de analizar las características literarias de este texto, se pueden realizar las siguientes actividades:

- Los estudiantes y la profesora leerán el texto en la clase.

- Posteriormente, la docente preguntará a los alumnos el orden de los acontecimientos, para verificar los primeros niveles de lectura: nivel literal y de reorganización de lo explícito.

- Seguidamente, los alumnos se formarán en subgrupos de cuatro integrantes. A cada subgrupo se le entregará en un papel una tarea por resolver. La docente también participa. Después de finalizada la tarea, deberán exponerla a sus compañeros. 


\section{- Tareas:}

1. A través de la construcción de un collage, ilustren el mundo interno de Edgar Allan Poe.

2. Expliquen mediante tres ejemplos, por qué "El gato negro" es un cuento y escríbanlas en un cartel.

3. Ejemplifiquen a través de citas textuales, tres características del Romanticismo presentes en el texto. Comenten si estas características se viven en el mundo actual. Ilustren en un cartel de qué manera.

4. Construyan un croquis en el que se representen los espacios físicos en los que se llevan a cabo los principales acontecimientos.

5. Expliquen qué es una metamorfosis. Ilustren, por etapas, la transformación que sufre el protagonista.

6. Comenten qué efectos causan el alcoholismo y la violencia del protagonista en su entorno. Investiguen de dónde proviene el término violencia.

7. ¿Qué tipos de maltratos reciben las mujeres en la actualidad? ¿Existen leyes que las protejan? ¿Cuáles?

8. Saben en qué consiste la "pena de muerte". Investiguen este proceso, paso a paso.

9. Tarea para la docente: Exponer sobre el término de la Perversidad, presente en el texto.

Al finalizar las tareas, los estudiantes las expondrán. La docente guiará los comentarios y cerrará el análisis.

\section{Tiempo}

6 lecciones

\section{Materiales}

- Cuento

- Hojas de papel para las tareas

- $\quad$ Para el collage (cartulina y recortes de revistas)

\section{Bibliografía}

- Poe, Edgar Allan. (1999). El gato negro. En Antología literaria. Clásicos Colección. Madrid España: Editorial Edimat.

Mediante estas actividades se puede cumplir con los objetivos y contenidos planteados por el MEP.

A través de la primera actividad: ver y discutir en clase la serie CSI, Las Vegas, se motiva y estimula al estudiante en el acercamiento al texto literario, ya que se parte de sus intereses próximos. Asimismo, disfruta de la lectura ya que él será un participante activo que reconstruirá los hechos ocurridos en el texto. De esta manera logrará disfrutar, ser creativo y crítico.

Por otra parte, a través de las tareas asignadas y la dinámica en subgrupos, el estudiante puede reconocer las características del texto. También, ilustrar la vida del autor, identificar el tipo de narrador, organizar los acontecimientos, reconocer los espacios en el texto, establecer y discutir la problemática que se plantea, identificar las características del género y movimiento literario.

$\mathrm{Al}$ fomentar una búsqueda como investigador del texto literario, el estudiante es capaz de comprender la pluralidad, la connotación y la relación del relato con su realidad personal. 


\section{Novela Marianela, de Benito Pérez Galdós}

Para analizar la novela Marianela se trabajará con el Diario de lectura.

La construcción de este diario se dio en la fase III de la propuesta desarrollada en el artículo Propuesta didáctica: Herramienta Metodológica y didáctica para analizar textos literarios con sétimos años (Ramírez, 2007).

Debido a la extensión de la novela, la docente asignará tareas que los estudiantes realizarán a través de la lectura del texto.

La primera actividad que se llevará a cabo, será retomar las características de la novela y el movimiento literario (RealismoNaturalismo) mediante una lluvia de ideas, guiada por la docente. Se retomará el tema debido a que fue analizado en el primer planeamiento de la fase IV, titulado: “Cómo realizar análisis literario?”.

Después de esta actividad, la profesora guiará a los estudiantes en la lectura del texto, comentará que la novela posee veintidós capítulos y que la historia se divide en tres partes:

1. La llegada del doctor Golfín al pueblo de Socartes.

2. La relación amorosa entre Pablo Penáguilas y Marianela.

3. Enfrentamiento con la realidad.

De esta manera, la docente ubicará a los alumnos en la historia, para que inicien con la lectura. Posteriormente, la profesora asignará en la clase las tareas, las cuales, contribuirán al desarrollo y al análisis de las siguientes dicotomías: Pobreza-riqueza, fealdad-belleza, imaginación-realidad, educación-ignorancia, campo-ciudad, humanismo-materialismo, vida-muerte, amorrechazo, entre otras.

En esta línea, cada tarea asignada por la docente y realizada por los alumnos abrirá el espacio de discusión y análisis de las dicotomías.
Este trabajo se realizará entre estudiantes y docente, es decir, el alumno realiza la tarea en su casa, en el diario de lectura, y la docente prepara una clase para la exposición de esa tarea y análisis de la dicotomía.

A continuación, se presentan las tareas y de qué manera se analizarán en clase.

\section{Tareas: desarrollo de dicotomías}

Para el desarrollo de las tareas y las dicotomías la idea es que, con los aportes de los estudiantes se construya una figura humana, para que, al finalizar el análisis, se pueda observar la novela como un todo. Es decir, de lo específico, partes del cuerpo: cabeza, tronco, extremidades, a lo general y así observar la novela integralmente. Los pedazos de papel de la figura humana serán construidos por la docente y se pegarán en desorden, en cualquiera de las cuatro paredes del aula. Al final, se unirán las partes.

1. La primera tarea que deberán realizar los estudiantes será describir el ambiente o espacio físico de la novela. Para ello buscarán una ilustración, lámina o recorte que plasme las características de la descripción del lugar. También pueden dibujar el ambiente.

Esta lámina o dibujo la llevarán a la clase. En la pizarra habrá un círculo de papel en blanco en el que los alumnos pegarán la ilustración o dibujo. Con las ilustraciones en el círculo, la docente preguntará qué tipo de ambiente se describe en la novela, asimismo, se discutirá la dicotomía campo-ciudad. ¿Cuáles son las semejanzas y diferencias entre estos espacios? y ¿Qué simbolizan en el texto? El círculo se pegará en alguna de las paredes del aula, porque luego se utilizará. 
2. La segunda tarea consiste en caracterizar física, psicológica y emocionalmente a los personajes de la novela. Los estudiantes deberán identificar sus conflictos o problemáticas y describirlos en el diario de lectura.

La docente les pedirá que lleven un recorte o fotografía de su ideal de belleza.

En otras dos lecciones, los estudiantes pegarán sus recortes en otra estructura de papel, facilitada por la docente.

Con el recorte que representa el ideal de belleza, se discutirá la dicotomía Fealdad-belleza. La docente realizará una breve aproximación al concepto de belleza y de fealdad. Se discutirá con el estudiante y, posteriormente, se trasladará a la problemática y caracterización de los personajes que plantea la novela.

3. La tercera tarea consiste en traer recortes alusivos a la pobreza y a la riqueza. Éstos se pegarán en las extremidades superiores de la figura humana. Con base en estos recortes se discutirá en la novela y en la realidad actual, la problemática de la pobreza, la explotación laboral, la injusticia social, la concentración del poder y la riqueza, la discriminación social y el analfabetismo.

4. La cuarta actividad consiste en caracterizar a las dos familias representadas en la novela: Los Penáguilas y los Centeno. En el diario de lectura los estudiantes establecerán las principales diferencias entre estas dos familias. Con base en dibujos o recortes las formarán y caracterizarán. Finalmente, pegarán, en las extremidades inferiores de la figura humana, sus trabajos.

En conjunto con la docente expondrán las diferencias.
5. Al finalizar con el análisis de las dicotomías, se unirán las partes de la figura humana, para que los alumnos puedan observar integralmente los elementos analizados por ellos. Este espacio será aprovechado por la docente para escuchar opiniones acerca de la novela y así cerrar el tema.

\section{Tiempo}

12 lecciones

\section{Materiales}

- La novela Marianela

- Recortes o dibujos

- Partes de la figura humana: cartulina o papel de presentación

- Cinta para pegar o goma.

\section{Bibliografía}

Pérez Galdós, Benito. Marianela. Clásicos Colección. Madrid, España. 2004.

\section{Rimas de Gustavo Adolfo Bécquer}

En el artículo Estrategias metodológicas utilizadas por docentes de sétimo año en la enseñanza del análisis de textos literarios se encontró que la manera en que es enseñada la poesía crea actitudes hostiles en los estudiantes. En las entrevistas que se realizaron a los alumnos, éstos expresan que el género que más les aburre es la poesía ya que deben memorizar las figuras literarias y de construcción, también hacer la métrica y la rima.

Esta apreciación demuestra que los aspectos formales de la poesía (figuras literarias, rima, métrica) se han convertido en el único tema importante por desarrollar 
en el aula, así se dejan de lado la oralidad, el análisis y la interpretación de este género del discurso. En esta línea surge la siguiente interrogante ¿Es posible que los estudiantes sientan aprecio y disfruten de la poesía como lo hacen de la música o del cine? Para que lo anterior sea posible se debe pensar en la poesía de otra manera, es decir, replantease la manera en que está siendo enseñada.

La poesía aporta modelos de lengua y de discurso a la vez que maneras de indagar sobre el mundo y sobre la condición humana. Por esta razón, la educación poética debe favorecer el acceso fluido del estudiante a los textos poéticos, en la medida en que en éstos no sólo se utiliza de una manera creativa el lenguaje, sino que también se refleja el diálogo del ser humano consigo mismo, con los otros y con su tiempo. De esta manera, el alumno puede encontrar en la poesía estereotipos, ideologías, estilos de vida y formas de entender y de hacer el mundo. En este sentido, la poesía no sólo es una experiencia estética de carácter personal sino también un tipo específico de comunicación y un hecho cultural compartido.

Carmen Barrientos Ruíz-Ruano, en su artículo Claves para una didáctica de la poesía (1999), señala:

La poesía, bien se lea, se escuche, se escriba o se recite, desempeña un importante papel educativo desde sus dimensiones comunicativa, lingüística, lúdica, estética, cultural y social (...) Algunas de las funciones de la poesía son:

- Amplía nuestras posibilidades comunicativas.

- Permite imaginar realidades diferentes de aquellas a las que estamos habituados.

- $\quad$ Enriquece nuestra capacidad de uso del lenguaje.

- Permite acceder a una forma de conocimiento diferente" (Barrientos, 1999, pp. 17-19).
Tomando en cuenta este aporte, ayudar a los estudiantes a desarrollar su capacidad para el análisis y la interpretación de textos poéticos, exige planificar con detenimiento un itinerario adecuado de aprendizajes literarios. También fomentar actitudes, ya que una actitud no puede enseñarse como se imparte un concepto, sino que ha de despertarse, ha de mostrarse el camino y ha de acompañarse para que los alumnos puedan desarrollar cierto grado de sensibilidad, y, con ello, puedan descubrir los beneficios que les aporta esta forma de comunicación.

En este sentido, el acercamiento al texto poético, dependerá del modo como se lleve a Bécquer a los adolescentes. La labor del profesor es ofrecer al alumno tantos recursos como sean necesarios para que, al utilizarlos desarrolle su competencia comunicativa. Al respecto, Víctor Moreno, en su artículo Textos poéticos en la educación secundaria (1999), afirma: "Un factor está en las manos del profesorado: Sólo si éste desea que la poesía entre en el aula, entrará" (Moreno, 1999, p. 43).

Con el propósito de lograr un acercamiento entre los estudiantes y este género literario, a continuación se proponen algunos cambios que se podrían implementar en los objetivos que el MEP plantea para estudiar el género lírico. También algunas actividades para analizar y disfrutar de las Rimas de Gustavo Adolfo Bécquer.

\section{Objetivos}

El estudiante es capaz de

- Escuchar atentamente el recitado de un poema.

- Recitar poemas y disfrutar con este tipo de actividad.

- Leer e interpretar poemas atendiendo a los distintos planos que entretejen el discurso poético.

- Enjuiciar los poemas leídos desde posturas personales críticas y creativas. 
- $\quad$ Acercarse a la poesía como una forma de conocimiento que le abre nuevas perspectivas.

- Entrar en contacto con la poesía de otras épocas y apreciar las distintas formas de sensibilidad estética que se manifiestan a través de este género del discurso.

- Reconocer la poesía como un valor cultural que pertenece a todos.

- Identificar poemas por sus características textuales y reconocer los elementos estructurales básicos.

- Establecer relaciones entre poemas, movimientos poéticos y elementos destacados del contexto cultural, social e histórico de los poemas.

\section{Actividades}

Las actividades que se proponen a continuación para analizar las Rimas, tienen como finalidad cumplir con los objetivos antes mencionados.

- La primera actividad se centrará en la lectura y escucha de poemas. Esta actividad tiene como propósito desarrollar actitudes comunicativas y valorativas orientadas a reconocer la poesía como un valor social y cultural que está relacionado con la capacidad de goce estético mediante la búsqueda de sentido.

Para leer, escuchar y hablar de los poemas, la docente se encargará de llevar algunas grabaciones de poesía. Los estudiantes escucharán atentamente los poemas. Luego, escribirán en una hoja qué les gustó o desagradó de estos poemas. Posteriormente se comentarán las opiniones. Se pueden utilizar poemas musicalizados y recreados con imágenes.

- También la docente puede llevar poemas que describan o representen escenas de la naturaleza o bien temáticas amorosas.
Los alumnos escucharán atentamente los poemas, y, posteriormente, a través de una ilustración, describirán cómo imaginan lo que dice el poema.

Para retroalimentar esta actividad, la docente solicitará a sus alumnos que traigan a la clase objetos relacionados con el mar o bien, con el amor. Cuando los estudiantes lleguen a la clase, habrá una ambientación del mar, con música, ilustraciones y algunos elementos que rodean este ambiente.

Sus aportes serán colocados dentro de la ambientación. Tendrán un tiempo en silencio para apreciarlo. Luego comentarán sobre qué les produjo la ambientación, qué imágenes o recuerdos despertó. Seguidamente recurrirán al poema en estudio, y compararán las imágenes experimentadas con las del poema.

Estas actividades son indispensables para iniciar la parte de análisis e interpretación.

- Después de escuchar y opinar sobre distintos poemas, el estudiante leerá en silencio las Rimas. Luego las leerá en voz alta.

La docente las leerá nuevamente. El estudiante las escuchará, atendiendo a la musicalidad de su lenguaje y expresará la impresión que le produce el ritmo de las poesías. También compartirá comentarios con respecto a las sensaciones y sentimientos experimentados durante la lectura.

- La docente solicitará a los estudiantes unirse en parejas. A cada pareja le asignará una tarea. Los alumnos deben responderla y exponerla ante el grupo.

\section{Tareas:}

1. Interprete el significado de la rima XVII. 
2. Imagine las características del hablante de la rima XXX.

3. Ubique el lugar y el tiempo de la rima XII.

4. Diferencie el tema y los subtemas de la rima IV.

5. Identifique los rasgos de la personalidad del poeta que han dejado huella en la rima LIII.

6. Subraye en cada rima la estrofa o el verso que expresa la idea principal.

7. Identifique los rasgos de la época del poeta que han dejado huella en la rima IV.

8. Escriba una frase de amor que imite este movimiento literario.

Con la exposición de cada respuesta se puede abrir un coloquio en el que se profundice en cada rima, es decir, es la oportunidad para que los estudiantes emitan juicios críticos sobre los poemas analizados. Los adolescentes se sienten a gusto con la poesía cuando leen un poema y descubren la comunicación de una experiencia que conecta con su propia experiencia, y cuando reconocen que sus experiencias son importantes por el hecho de verlas reflejadas en los poemas leídos.

Concluida esta etapa, la docente iniciará con la explicación de los conceptos formales del género lírico.

Expondrá sobre los conceptos de rima, métrica y figuras literarias.

\section{Tiempo}

10 lecciones

\section{Materiales}

- Rimas

- Radio grabadora

- Hojas de papel

- Ilustraciones sobre el mar o el amor

- Discos (CD)

\section{Bibliografía}

- Bécquer, Gustavo Adolfo. Rimas. Obras selectas (2000). Madrid. España.

\section{Conclusiones}

- La falta de un ordenamiento metodológico, tanto en el nivel de los conceptos como en términos de los contenidos programados, puede impedir que el estudiante se relacione directamente con el objeto de estudio, ya que ofrece temas alejados de sus intereses vitales o conceptos que no significan un reto para sus estructuras cognoscitivas en proceso de desarrollo. También la metodología empleada por algunos docentes imprime un carácter unidireccional en la enseñanza, ya que el aprendizaje no es sólo la adquisición de técnicas instrumentales y de destrezas básicas, sino también el resultado de procesos de interpretación y de comprensión que faciliten la construcción por parte del alumno.

- $\quad$ Existen grandes vacíos metodológicos en el momento se enseñar ya que el objetivo planteado por el MEP señala que el estudiante debe reconocer la lengua literaria como un sistema ficcional, connotativo, plurisignificativo, dialógico cultural, y, además, que la comprensión de todo texto implica una competencia del lector como sujeto participante, para enriquecer su actividad de percepción y de descriframiento (MEP, 2005, p. 25).

Sin embargo, en el artículo Estrategias metodológicas utilizadas por docentes de sétimo año en la enseñanza del análisis de textos literarios se evidencia que entre el programa planteado para la enseñanza del Español y lo que sucede en realidad en las aulas, existe una gran distancia. Si bien se 
pretende que el estudiante logre comprender la importancia de la lengua literaria, lo que hace en la clase es recibir tareas de lectura centradas en el texto, aprender cómo se contestan preguntas, realizar un examen, hacer un esquema o un resumen y, además, repetir, y parafrasear, de forma parcial o total, la información.

- Las estrategias metodológicas utilizadas por las docentes para analizar los textos literarios les sirven y por eso las han adoptado aunque no se promuevan situaciones donde la literatura se vea arropada por su verdadera función social y cultural. Como resultado no se impulsa la participación activa de los estudiantes en actos de intercambio que tengan propósitos explícitos pero sí se practican planteamientos que otorgan a la literatura una naturaleza restrictiva y no representativa, privada de su relación con el contexto, porque éste aparece como mero fondo en el que los hechos literarios ocurren sin vínculos.

- Cuando los alumnos se están iniciando en el género lírico, es difícil que puedan acceder por sí solos al sentido de un poema mediante una lectura silenciosa del mismo; de ahí que sea preciso ayudarles a buscar ese sentido.

Para que los estudiantes perciban la poesía o cualquier otro género, como una forma de comunicación es preciso crear en el aula situaciones de lectura que les permitan convertirse en receptores de una experiencia que les habla de ellos mismos y de su relación con la realidad desde perspectivas diferentes.

\section{Referencias bibliográficas}

Barrientos, C. (1999). "Claves para una didáctica de la poesía”. Textos de didáctica de la lengua y de la literatura, 21(1): 17-34.

Bécquer, G. A. (2000). Rimas. Obras selectas. Madrid, España: Editorial Edimat.

Bustos P., G. (2000). Vamos a leer. Cuaderno pedagógico de español II para Noveno. Ministerio de Educación Pública. San José: Centro Nacional de Didáctica.

Ministerio de Educación Pública. (2005). Programa de estudios. Español I y II ciclo de Educación General Básica. San José, Costa Rica: Departamento de Publicaciones, Ministerio de Educación Pública.

Moreno, V. (1999). Textos poéticos en la educación secundaria. Textos de didáctica de la lengua y de la literatura, 21(1): 35-47.

Pérez G., B.. (2004) Marianela. Clásicos Colección. Madrid España: Editorial Edimat.

Poe, E. A. (1999). El gato negro. En Antología literaria. Clásicos Colección. Madrid, España: Editorial Edimat.

Ramírez M., C. (2007). Estrategias metodológicas utilizadas por las docentes de sétimo año en la enseñanza del análisis de textos literarios en el Liceo de Heredia. Tesis de Licenciatura: Universidad de Costa Rica, Costa Rica.

Vargas, L., Bustillos, G. y Marfán, Ml. (1984). Técnicas participativas para la educación popular. Tomos I y II. San José: Alforja. 